\title{
KARAKTERISASI DISSOLVED ORGANIC MATTER (DOM) DI PANTAI PARIWISATA DAN PANTAI NATURAL
}

\author{
I Gusti Ngurah Agung Suryaputra \\ Program Studi Analis Kimia, Universitas Pendidikan Ganesha \\ Singaraja, Bali, Indonesia \\ e-mail: surya@fulbrightmail.org
}

\begin{abstract}
Abstrak
Penelitian ini bertujuan untuk mengetahui perbedaan karakter dissolved organic matter (DOM) pada pantai pariwisata yang didominasi oleh kegiatan hotel dan rumah makan, pantai pariwisata yang didominasi oleh wisata air, dan pantai natural di pesisir Utara Buleleng. DOM diukur dalam bentuk dissolved organic carbon (DOC) menggunakan Shimadzu TOC-L Analyzer dan chromophoric dissolved organic matter (CDOM) menggunakan Shimadzu UV-1800 Spectrophotometer. Selain itu, konsentrasi nutrien terlarut dalam air dianalisis menggunakan Palintest, dan $\mathrm{pH}$ dan oksigen terlarut diukur secara in-situ menggunakan sensor. Hasil penelitian menunjukkan bahwa konsentrasi nutrien dari tertinggi ke terendah ditemukan berturut-turut pada pantai pariwisata yang didominasi kegiatan hotel dan rumah makan, pantai pariwisata yang didominasi kegiatan wisata air, dan pantai natural. Hasil analisis DOM dalam bentuk DOC dan CDOM mengindikasikan bahwa pantai pariwisata yang didominasi kegiatan hotel dan rumah makan memiliki karakteristik DOM yang paling berbeda, yang dipengaruhi oleh kegiatan pariwisata terkait. DOM pada pantai ini memiliki sifat kurang aromatis, lebih labil, dan memiliki berat molekul lebih tinggi.
\end{abstract}

Kata kunci: karakteristik DOM, nutrien, pantai pariwisata, pantai natural

\begin{abstract}
The objective of this research was to determine the differences of dissolved organic matter (DOM) on tourism beach which was dominated by hotel and restaurant activities, tourism beach which was dominated by water-based tourism, and natural beaches on the North coast of Bali Island. DOM was measured in the form of dissolved organic carbon (DOC) using a Shimadzu TOC-L Analyzer and chromophoric dissolved organic matter (CDOM) using a Shimadzu UV-1800 Spectrophotometer. In addition, dissolved nutrient concentrations in water were analyzed using Palintest, and $\mathrm{pH}$ and dissolved oxygen were measured in-situ using a sensor. The results showed that the highest to lowest nutrient concentrations were found on the tourism beach which was dominated by hotel and restaurant activities, the tourism beach which was dominated by water tourism activities, and the natural beach, respectively. DOM analyses indicate that tourism beach which is dominated by hotel and restaurant activities have the most different DOM characteristics, which are influenced by related tourism activities. The DOM on these beaches is less aromatic, more volatile, and has a higher molecular weight.
\end{abstract}

Keywords: DOM characteristic, nutrient, tourism-dominated beach, natural beach

\section{PENDAHULUAN}

Pantai menjadi salah satu tujuan wisatawan untuk berlibur maupun untuk melakukan olahraga air. Semakin meningkatnya aktivitas pariwisata di pantai membuat para investor membangun berbagai fasilitas berlibur seperti pembangunan hotel dan restoran di sekitar pantai. Hal tersebut dapat berdampak terhadap pencemaran lingkungan. Limbah dari kegiatan pariwisata, seperti buangan hotel, restoran dan lain-lain, dapat mengganggu ekosistem yang ada di pantai, baik secara langsung maupun tidak langsung. Keberadaan bahan pencemar, terutama bahan organik, mempengaruhi kadar oksigen terlarut dalam air. Kelimpahan bahan organik dalam perairan 
akan mengakibatkan mikroba membutuhkan banyak oksigen untuk mengoksidasi bahan organik di perairan, sehingga mengakibatkan kadar Dissolved Oxygen (DO) menurun (Effendi, 2003).

Aktivitas manusia juga berpengaruh terhadap dissolved organic matter (DOM), yang merupakan salah satu sumber utama dari bahan organik pada permukaan bumi (Hedges, 2002) dan bertanggung jawab menyerap sinar ultraviolet (UV) yang berbahaya bagi kehidupan di perairan (Blough dan Del Vecchio, 2002). Di sungai yang mendapat pengaruh urbanisasi dan industrialisasi, perubahan karakter DOM bisa diamati melalui sifat optik dan komposisi molekulnya (He et al., 2019). Perubahan ini secara spesifik terlihat dari fluoresensi DOM, pada komponen proteinlike (Yang et al., 2013) maupun dalam bentuk kombinasi puncak (Tzortziou et al., 2015).

Selain DOM, aktivitas manusia juga mempengaruhi keberadaan nutrien terlarut. Nutrien terlarut terdiri atas nitrogen anorganik terlarut dan fosfor anorganik terlarut. Nitrogen anorganik terlarut terdapat dalam bentuk ammonia $\left(\mathrm{NH}_{3}\right)$, nitrat $\left(\mathrm{NO}_{3}{ }^{-}\right)$, dan nitrit $\left(\mathrm{NO}_{2}{ }^{-}\right)$; dan fosfor anorganik terlarut terdapat dalam bentuk ortofosfat $\left(\mathrm{PO}_{4}{ }^{3-}\right)$ (Alianto et al., 2009). Kelimpahan nutrien dapat meningkatkan total produksi ikan dan bahkan memperbesar potensi muncul dan berkembangnya jenis fitoplankton berbahaya yang lebih umum dikenal dengan istilah Harmful Algal Blooms (HABs) (Gypens et al., 2011).
Namun, sampai saat ini belum ada yang mempelajari pengaruh aktivitas pariwisata terhadap karakteristik DOM secara khusus dan pengaruhnya pada komposisi nutrien. Untuk itu, penelitian ini akan mempelajari pengaruh kegiatan pariwisata terhadap karakteristik DOM dan komposisi nutrien.

\section{METODE}

Sampel diambil dari tiga lokasi di Pantai Utara Pulau Bali dengan menggunakan teknik purposive sampling. Kriteria yang ditetapkan pada masingmasing lokasi tersebut adalah a). pantai pariwisata I adalah pantai yang didominasi oleh kegiatan hotel dan rumah makan yaitu terdapat 2 atau lebih hotel dan rumah makan di pesisir pantai; b). pantai pariwisata II adalah pantai yang sering dikunjungi untuk wisata air seperti berenang dan olahraga kano dan tidak ada kegiatan hotel; dan c) pantai natural adalah pantai yang bebas dari kegiatan manusia baik untuk wisata air ataupun kegiatan perhotelan (Gambar 1). Sampel air diambil dari permukaan air pantai dengan menggunakan ember. Sampel kemudian disaring menggunakan kertas saring GF/F 0,7 $\mu \mathrm{m}$ dengan bantuan pompa vakum ke dalam botol gelas dan disimpan dalam freezer sampai saatnya dianalisis. Saat pengambilan sampel, dilakukan pengukuran salinitas, dissolved oxygen (DO), dan $\mathrm{pH}$ menggunakan Hanna Water Quality Sensor.

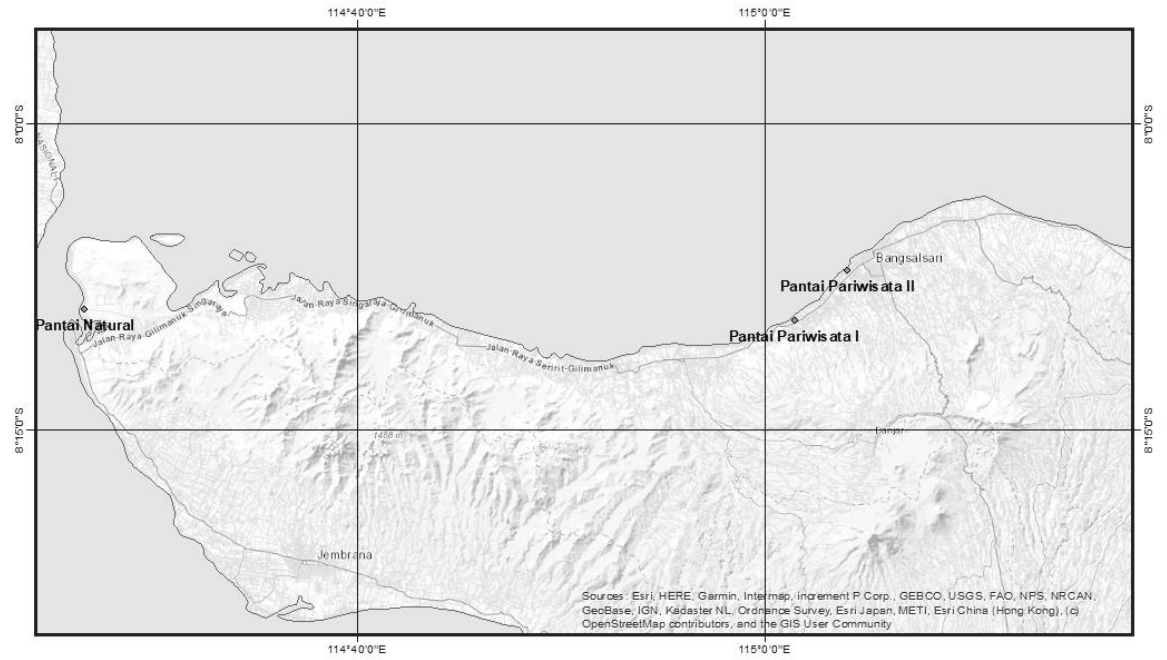

Gambar 1. Tempat Pengambilan Sampel. 
Sebelum pengukuran nutrien, sampel dibiarkan dulu mencapai suhu kamar. Pengukuran nutrien menggunakan metode palintest. Pada pengujian amonium, sebanyak $10 \mathrm{~mL}$ sampel dimasukkan ke dalam tabung. Selanjutnya ditambahkan reagen nessler sebanyak 12 tetes dan larutan dicampur. Larutan didiamkan selama 1 menit dan kemudian absorbansi dibaca pada panjang gelombang $410 \mathrm{~nm}$. Pada pengujian nitrat, sebanyak $20 \mathrm{~mL}$ sampel dimasukkan ke dalam gelas beker, kemudian ditambahkan satu sendok nitrat powder untuk mereduksi nitrat menjadi nitrit. Sampel didiamkan selama 2 menit kemudian dipipet sebanyak $10 \mathrm{~mL}$ dan dimasukkan ke dalam tabung. Selanjutnya ditambahkan nitricol tablets dan diaduk hingga larut. Larutan didiamkan selama 10 menit dan kemudian dibaca pada panjang gelombang $520 \mathrm{~nm}$. Pada pengujian nitrit, sebanyak $10 \mathrm{~mL}$ sampel dimasukkan ke dalam tabung dan kemudian ditambahkan nitricol tablets. Tablet dihancurkan dan dicampur hingga terlarut, selanjutnya larutan didiamkan selama 10 menit dan kemudian dibaca pada panjang gelombang $570 \mathrm{~nm}$. Pada pengujian fosfat, ke dalam $50 \mathrm{~mL}$ sampel diteteskan indikator fenolftalin. Apabila timbul warna merah, larutan ditambahkan $\mathrm{H}_{2} \mathrm{SO}_{4} 5 \mathrm{~N}$ tetes demi tetes sampai warnanya hilang. Selanjutnya ditambahkan $8 \mathrm{~mL}$ campuran $50 \mathrm{~mL} \mathrm{H}_{2} \mathrm{SO}_{4}$ $5 \mathrm{~N}, 5 \mathrm{~mL}$ larutan kalium antimonil tartrat, 15 $\mathrm{mL}$ larutan amonium molibdat, dan $30 \mathrm{~mL}$ larutan asam askorbat. Larutan diaduk hingga homogen dan diukur absorbansinya pada panjang gelombang $780 \mathrm{~nm}$.

Selain nutrien, dilakukan juga pengukuran DOM dalam bentuk dissolved organic carbon (DOC) dan chromophoric dissolved organic matter (CDOM). Sebelum pengukuran, sampel dibiarkan terlebih dahulu mencapai suhu kamar. Pada pengukuran $\mathrm{DOC}, \mathrm{HCl}$ 0,1 $\mathrm{M}$ ditambahkan ke dalam sampel sampai mencapai $\mathrm{pH} 2$ kemudian dilanjutkan dengan pengukuran menggunakan Shimadzu TOC-L Analyzer.
Pada pengukuran CDOM, sampel diukur absorbansinya menggunakan Shimadzu UV-1800 Spectrophotometer dengan melakukan scanning pada panjang gelombang 200-800 nm, dengan kenaikan setiap panjang gelombang $0,5 \mathrm{~nm}$. Data absorbasi CDOM kemudian dianalisis dalam bentuk SUVA 280 (Peuravuori et al., 2005), spectral slope (Helms et al., 2008), slope ratio $\left(S_{R}\right)$ (Helms et al., 2008), serta perbandingan absorbansi $\mathrm{E}_{2}: \mathrm{E}_{3}$ (Ågren et al., 2008; Dahlén et al., 1996) dan $\mathrm{E}_{4}: \mathrm{E}_{6}$ (Chen et al., 2002).

\section{HASIL DAN PEMBAHASAN}

Hasil pengukuran parameter secara in-situ menunjukkan nilai $\mathrm{DO}$ dan $\mathrm{pH}$ yang hampir sama pada ketiga lokasi. Namun, pantai yang didominasi oleh kegiatan hotel dan rumah makan menunjukkan salinitas yang lebih kecil (Tabel 1). Hal ini mengindikasikan bahwa ada masukan air tawar pada pantai. Masukan ini bukan berasal dari air tanah yang mempunyai $\mathrm{pH}$ antara 7-8 (Macpherson, 2009), namun berasal dari aktivitas hotel dan rumah makan seperti limbah laundry, kolam renang, dan sejenisnya.

Tabel 1. Data hasil pengukuran parameter $\mathrm{DO}, \mathrm{pH}$, salinitas dan koordinat pengambilan sampel

\begin{tabular}{lcc}
\hline \multicolumn{1}{c}{ Sampel } & $\mathrm{DO}, \mathrm{mg} \cdot \mathrm{L}^{-1}$ & $\mathrm{pH}$ \\
\hline Pariwisata I & 4,07 & 8,50 \\
Pariwisata II & 3,80 & 8,53 \\
Natural & 3,93 & 8,67 \\
\hline
\end{tabular}

dan $\begin{gathered}\text { Nutrien, baik nitrat, nitrit, amonium, } \\ \text { fosfat secara konsisten }\end{gathered}$ memperlihatkan konsentrasi tertinggi pada Pantai Pariwisata I, yang disusul oleh Pantai Pariwisata II, dan Pantai Natural (Gambar 2). Hal ini mengindikasikan bahwa kegiatan pariwisata, khususnya hotel dan rumah makan, merupakan sumber masukan nutrien di daerah pantai. 

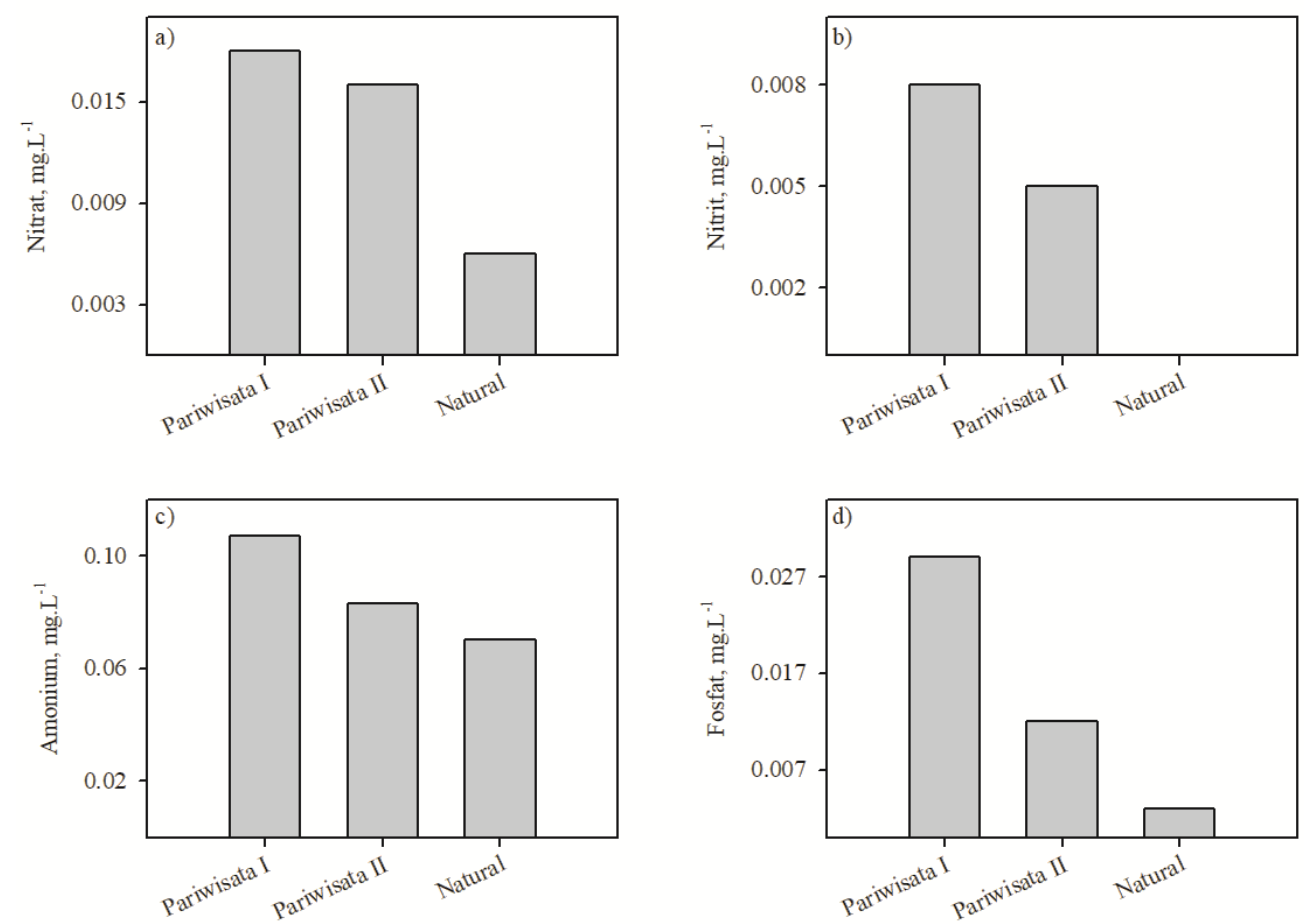

Gambar 2. Konsentrasi nitrat (a), nitrit (b), amonium (c), dan fosfat (d) pada Pantai Pariwisata I, Pantai Pariwisata II, dan Pantai Natural.

Hasil pengukuran DOC menunjukkan konsentrasi tertinggi berada pada Pantai Pariwisata I, disusul oleh Pantai Pariwisata II dan Pantai Natural (Gambar 3, kiri). Hal ini menunjukkan bahwa aktivitas pariwisata, terutama aktivitas hotel dan rumah makan, memberikan kontribusi pada peningkatan konsentrasi DOC di pantai. SUVA 280 pada Pantai Pariwisata I memperlihatkan nilai

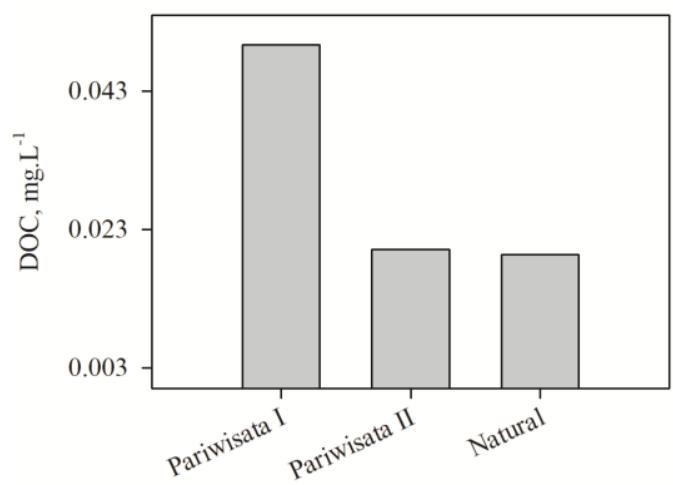

yang jauh lebih rendah dibandingkan SUVA $_{280}$ pada Pantai Pariwisata II dan Pantai Natural (Gambar 3, kanan). Hal ini menegaskan bahwa DOC pada Pantai Pariwisata I berasal dari zat-zat organik yang kurang aromatis dan lebih labil dibandingkan kedua pantai lainnya.

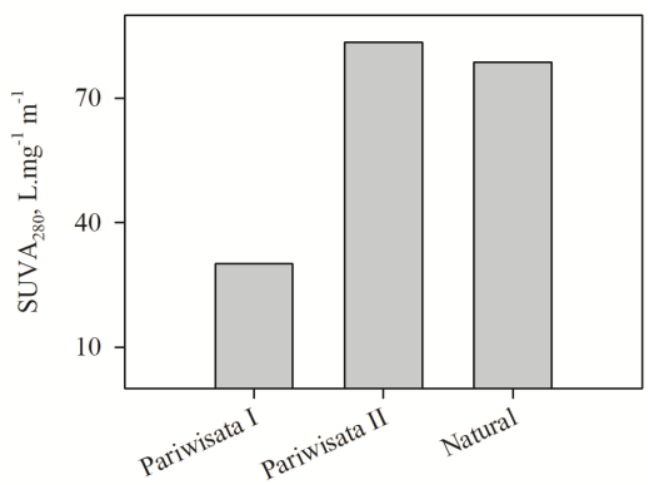

Gambar 3. Konsentrasi dissolved organic carbon (DOC) (kiri) dan SUVA 280 (kanan) pada Pantai Pariwisata I, Pantai Pariwisata II, dan Pantai Natural.

Kowalczuk et al. (2010) menggunakan absorbansi pada $350 \mathrm{~nm}$ untuk menunjukkan sifat terrigenous pada DOC. Semakin tinggi absorbansi pada panjang gelombang tersebut, maka semakin tinggi pula sifat terrigeneous pada DOC tersebut. Dari hasil pengukuran, ketiga pantai tidak menunjukkan absorbansi yang jauh Jurnal Sains dan Teknologi | 64 
berbeda (Gambar 4a), yang menandakan bahwa DOC pada ketiga pantai tersebut memang hanya dipengaruhi oleh aktivitas pariwisata dan tidak dipengaruhi oleh masukan dari sungai ataupun air tanah. Hal ini juga diperkuat dengan nilai perbandingan $E_{2}: E_{3}$ yang merupakan indikasi ukuran molekul DOC dan nilai perbandingan $E_{4}: E_{6}$ yang merupakan indikasi humifikasi. Jika di salah satu pantai mendapatkan masukan dari air sungai atau air tanah, maka ukuran DOC akan semakin besar dan humifikasi akan semakin tinggi. Dengan tidak adanya perbedaan perbandingan $\mathrm{E}_{2}: \mathrm{E}_{3}$ (Gambar $4 \mathrm{~b}$ ) dan $\mathrm{E}_{4}: \mathrm{E}_{6}$ (Gambar 4c) yang mencolok pada ketiga pantai tersebut, maka bisa disimpulkan bahwa tidak ada satupun pantai yang mendapat masukan dari air sungai ataupun air tanah.

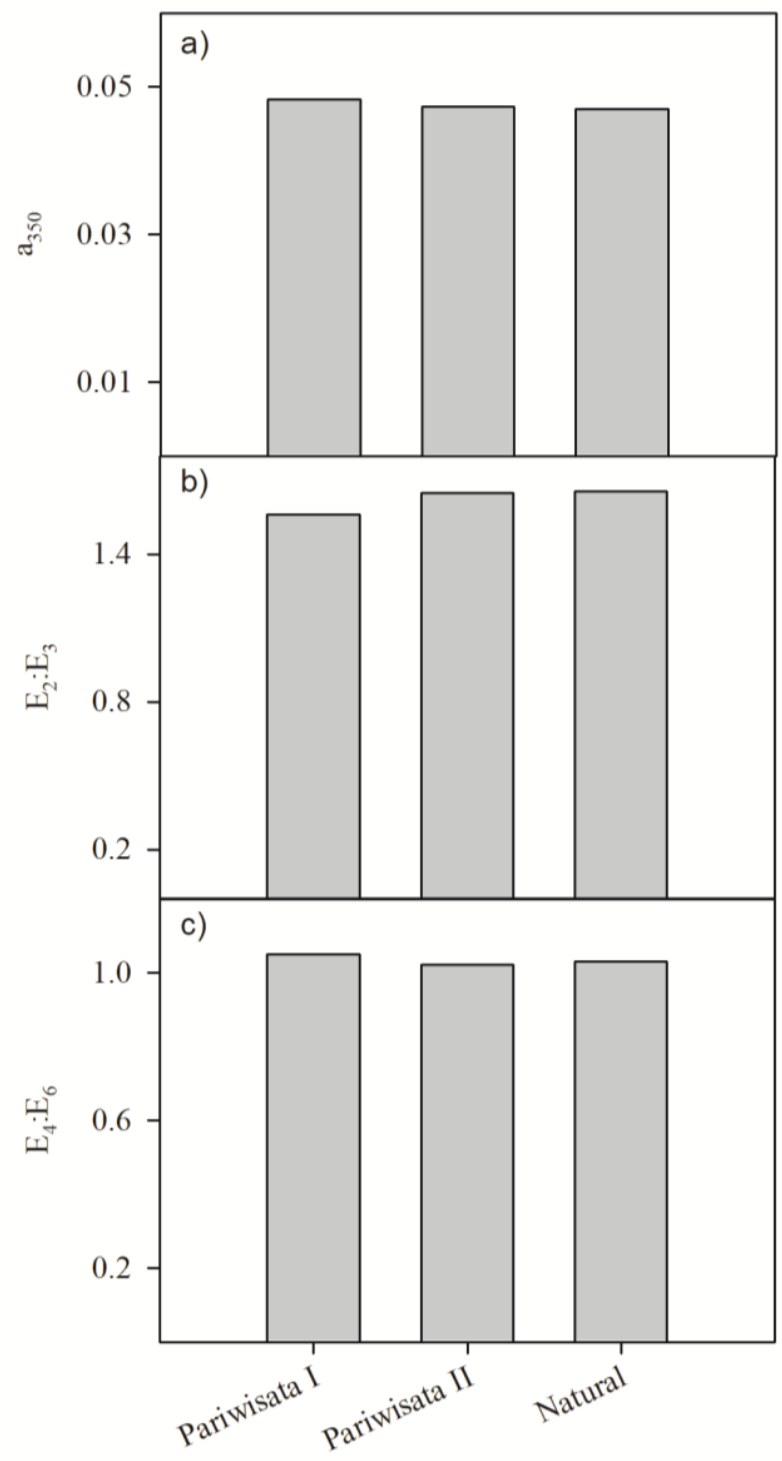

Gambar 4. Absorbansi pada panjang gelombang $350 \mathrm{~nm}$ (a), perbandingan absorbansi pada panjang gelombang $250 \mathrm{~nm}$ dan $365 \mathrm{~nm}$ (b), dan perbandingan absorbansi pada panjang gelombang $465 \mathrm{~nm}$ dan $665 \mathrm{~nm}$ (c).

Selain menggunakan absorbansi dan perbandingannya, komposisi DOM juga bisa dijelaskan dengan menggunakan spectral slope, salah satunya adalah yang dihitung pada kisaran panjang gelombang
275-295 nm (Helms et al., 2008). Pada penelitian ini, nilai S275-295 pada Pantai Pariwisata I menunjukkan perbedaan jika dibandingkan dengan kedua pantai lainnya (Gambar 5). Rendahnya nilai spectral slope 
ini mengindikasikan bahwa berat molekul DOM pada Pantai Pariwisata I lebih tinggi dibandingkan pada kedua pantai lainnya.

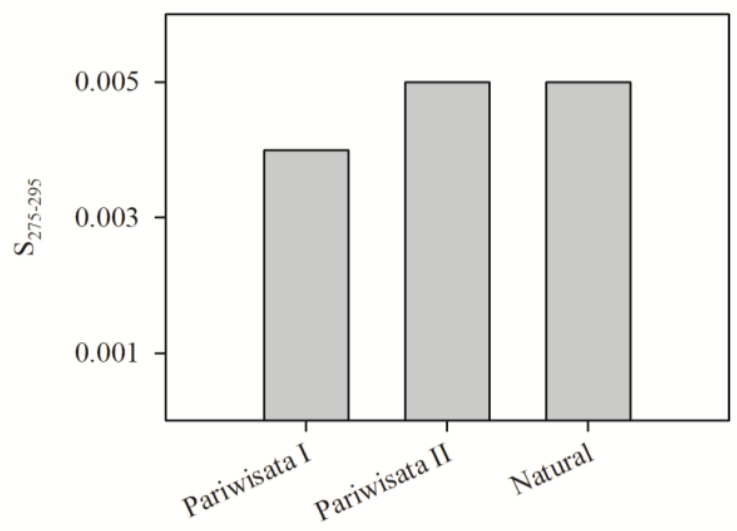

Gambar 5. Spectral slope yang ditentukan pada kisaran panjang gelombang 275-295 nm.

\section{SIMPULAN}

Sampel yang diambil dari ketiga lokasi menunjukkan bahwa tidak ada masukan air sungai maupun air tanah pada pantainya. Walaupun demikian, pantai yang didominasi oleh kegiatan pariwisata berupa hotel dan rumah makan mempunyai karakteristik dissolved organic matter (DOM) yang berbeda dibandingkan pantai yang didominasi kegiatan pariwisata untuk wisata air dan pantai natural. DOM pada pantai ini memiliki sifat kurang aromatis, lebih labil, dan memiliki berat molekul lebih tinggi sehingga dapat disimpulkan bahwa karakter DOM ini dipengaruhi oleh aktivitas hotel dan rumah makan seperti limbah laundry, kolam renang, dan sejenisnya. Aktivitas-aktivitas ini juga meningkatkan konsentrasi nutrien di pantai.

\section{UCAPAN TERIMAKASIH}

Suryaputra mengucapkan terima kasih kepada Universitas Pendidikan Ganesha yang telah membiayai penelitian ini. Suryaputra juga mengucapkan terima kasih kepada Ni Made Defy Janurianti yang telah membantu dalam pengambilan dan pengukuran sampel.

\section{DAFTAR PUSTAKA}

Ågren, A., Buffam, I., Berggren, M., Bishop, K., Jansson, M., \& Laudon, H. (2008). Dissolved organic carbon characteristics in boreal streams in a forest-wetland gradient during the transition between winter and summer. Journal of Geophysical Research: Biogeosciences, 113(G3).

Alianto, A., Adiwilaga, E. M., Damar, A., \& Harris, E. (2010). Measurement of Dissolved Inorganic Nutrient in Euphotic Zone The Banten Bay. Indonesian Journal of Chemistry, 9(2), 217-225.

Blough, N.V., \& Del Vecchio, R. (2002). Distribution and dynamics of chromophoric dissolved organic matter (CDOM) in the coastal environment. In: Hansell, D., Carlson, C. (Eds.). Biochemistry of Marine Dissolved Organic Matter. Academic Press, Amsterdam, pp. 509 - 546.

Chen, J., Gu, B., LeBoeuf, E. J., Pan, H., \& Dai, S. (2002). Spectroscopic characterization of the structural and functional properties of natural organic matter fractions. Chemosphere, 48(1), 59-68.

Dahlén, J., Bertilsson, S., \& Pettersson, C. (1996). Effects of UV-A irradiation on dissolved organic matter in humic surface waters. Environment International, 22(5), 501-506.

Effendi, H. (2003). Telaah kualitas air, bagi pengelolaan sumber daya dan lingkungan perairan. Kanisius.

Gypens, N., Lacroix, G., Lancelot, C., \& Borges, A. V. (2011). Seasonal and inter-annual variability of air-sea $\mathrm{CO} 2$ fluxes and seawater carbonate chemistry in the Southern North Sea. Progress in oceanography, 88(14), 59-77.

He, D., He, C., Li, P., Zhang, X., Shi, Q., \& Sun, Y. (2019). Optical and molecular signatures of dissolved organic matter reflect anthropogenic influence in a coastal river, Northeast China. Journal of environmental quality, 48(3), 603613.

Hedges, J. I. (2002). Why dissolved organics matter?. Biogeochemistry of marine dissolved organic matter, 1-33.

Helms, J. R., Stubbins, A., Ritchie, J. D., Minor, E. C., Kieber, D. J., \& Mopper, K. (2008). Absorption spectral slopes 
and slope ratios as indicators of molecular weight, source, and photobleaching of chromophoric dissolved organic matter. Limnology and oceanography, 53(3), 955-969.

Macpherson, G. L. (2009). CO2 distribution in groundwater and the impact of groundwater extraction on the global $\mathrm{C}$ cycle. Chemical Geology, 264(1-4), 328-336.

Peuravuori, J., Monteiro, A., Eglite, L., \& Pihlaja, K. (2005). Comparative study for separation of aquatic humic-type organic constituents by DAX-8, PVP and DEAE sorbing solids and tangential ultrafiltration: elemental composition, size-exclusion chromatography, UV-vis and FTIR. Talanta, 65(2), 408-422.

Tzortziou, M., Zeri, C., Dimitriou, E., Ding, Y., Jaffé, R., Anagnostou, E., ... \& Mentzafou, A. (2015). Colored dissolved organic matter dynamics and anthropogenic influences in a major transboundary river and its coastal wetland. Limnology and oceanography, 60(4), 1222-1240.

Yang, L., Hong, H., Chen, C. T. A., Guo, W., \& Huang, T. H. (2013). Chromophoric dissolved organic matter in the estuaries of populated and mountainous Taiwan. Marine Chemistry, 157, 12-23. 